\title{
Cruciferous vegetables and colo-rectal cancer
}

\author{
Anthony Lynn ${ }^{1}$, Andrew Collins ${ }^{2}$, Zoë Fuller ${ }^{3}$, Kevin Hillman ${ }^{4}$ and Brian Ratcliffe ${ }^{1}$ \\ ${ }^{1}$ The Robert Gordon University, St Andrew Street, Aberdeen AB25 1HG, UK \\ ${ }^{2}$ University of Oslo, Blindern, N-0316 Oslo, Norway \\ ${ }^{3}$ The Macaulay Institute, Craigiebuckler, Aberdeen AB15 8QH, UK \\ ${ }^{4}$ The Scottish Agricultural College, Craibstone, Aberdeen AB21 9YA, UK
}

\begin{abstract}
Cruciferous vegetables have been studied extensively for their chemoprotective effects. Although they contain many bioactive compounds, the anti-carcinogenic actions of cruciferous vegetables are commonly attributed to their content of glucosinolates. Glucosinolates are relatively biologically inert but can be hydrolysed to a range of bioactive compounds such as isothiocyanates (ITC) and indoles by the plant-based enzyme myrosinase, or less efficiently by the colonic microflora. A number of mechanisms whereby ITC and indoles may protect against colo-rectal cancer have been identified. In experimental animals cruciferous vegetables have been shown to inhibit chemicallyinduced colon cancer. However, the results of recent epidemiological cohort studies have been inconsistent and this disparity may reflect a lack of sensitivity of such studies. Possible explanations for the failure of epidemiological studies to detect an effect include: assessment of cruciferous vegetable intake by methods that are subject to large measurement errors; the interaction between diet and genotype has not been considered: the effect that post-harvest treatments may have on biological effects of cruciferous vegetables has not been taken into account.
\end{abstract}

Cruciferous vegetables: Broccoli: Colo-rectal cancer

Colo-rectal cancer (CRC) is a major public health burden in Westernised societies. In the UK $>33000$ new cases are diagnosed each year (Quinn et al. 2001). Inherited cancer syndromes, such as familial adenomatous polyposis, account for $5-10 \%$ CRC, but most appear to arise sporadically (Lynch \& de la Chapelle, 2003). A number of environmental factors appear to influence risk, including alcohol intake, smoking, physical activity, non-steroidal anti-inflammatory drugs and diet (Giovannucci et al. 1994; Colditz et al. 1997; World Cancer Research Fund, 1997; Giovannucci, 2001).

Estimates vary, but $\leq 80 \%$ of the sporadic CRC may be attributable to diet (Bingham, 2000). Epidemiological and experimental studies have identified a number of putative risk factors and protective factors in the human diet. For example, some studies indicate that diets high in fat and meat may increase risk, whereas diets high in dietary fibre and vegetables may be protective (World Cancer Research Fund, 1997; Bingham et al. 2003; International Agency for Research on Cancer, 2003).

Cruciferous vegetables, which include the genus Brassica, have received much interest as possible cancer-protective components of the human diet (Verhoeven et al. 1996, 1997). In the mid 1990s a number of epidemiological reviews concluded that the consumption of cruciferous or brassica vegetables is associated with a reduced risk of CRC (Steinmetz \& Potter, 1996; Verhoeven et al. 1996; Kohlmeier \& Su, 1997). However, at that time few results from cohort studies had been published, but more recent cohort studies have cast doubt on the strength of the inverse association between cruciferous vegetable intake and CRC (Steinmetz et al. 1994; Hsing et al. 1998; Pietinen et al. 1999; Michels et al. 2000; Voorrips et al. 2000; Flood et al. 2002; McCullough et al. 2003). However, in animal models of colon cancer cruciferous vegetables have consistently been shown to exhibit anti-carcinogenic effects (International Agency for Research on Cancer, 2004).

\section{Mechanisms through which cruciferous vegetables may protect against colo-rectal cancer}

Cruciferous vegetables contain a number of bioactive components such as folate, vitamin $\mathrm{C}$, tocopherols, carotenoids and polyphenols (DeSouza \& Eitenmiller, 1986; Price et al. 1998; Kurilich et al. 1999). However, the anti-carcinogenic actions of cruciferous vegetables are most frequently attributed to their content of glucosinolates

\footnotetext{
Abbreviations: ACF, aberrant crypt foci; CRC, colo-rectal cancer; CYP, cytochrome P; DMH, 1,2-dimethylhydrazine; GLS, glucosinolates; GST, glutathione S-transferases; I3C, indole-3-carbinol; IQ, 2-amino-3-methylimidazo[4,5- $f$ ] quinoline; ITC, isothiocyanates. 
(GLS; van Poppel et al. 1999; Lampe \& Peterson, 2002). GLS are a group of compounds that have a common basic structure of a $\beta$-D-thioglucose and a sulfonated oxime moiety, but differ in the structure of their side chains, which may be aliphatic, aromatic or heterocyclic (Mithen et al. 2000; Holst \& Williamson, 2004). GLS are historically regarded as biologically inert, but can be hydrolysed to a range of more bioactive products (Johnson, 2002a). The hydrolysis of GLS is largely dependent on the activity of a plant-based $\beta$-D-thioglucosidase enzyme, myrosinase (Bones \& Rossiter, 1996). GLS and myrosinase appear to be separated within plant cells but they come into contact with each other on disruption of the cells. Myrosinase then catalyses the hydrolysis of the thioglucose bond leading to the production of an unstable aglucone that undergoes spontaneous rearrangement to form a range of breakdown products such as isothiocyanates (ITC), nitriles and S, oxazolidine-2-thiones and indolyl compounds (Holst \& Williamson, 2004). The product formed depends on the side-chain structure of the parent GLS, $\mathrm{pH}$, the presence of $\mathrm{Fe}^{2+}$ and, in the case of some GLS, the presence of a cofactor, epithiospecifier protein (Bones \& Rossiter, 1996; Matusheski et al. 2004).

The mechanisms through which cruciferous vegetables and their GLS breakdown products may protect against CRC include the modulation of xenobiotic-metabolising enzymes, antioxidant effects, the induction of apoptosis and cell cycle arrest (Plumb et al. 1997; van Poppel et al. 1999; Smith et al. 2003, 2005).

\section{Modulation of xenobiotic-metabolising enzymes}

Chemical carcinogens can be classified as either direct acting or indirect acting, with the latter being the most common (Hodgson \& Akunda, 2001). The activation and detoxification of carcinogens is largely catalysed by the phase 1 and phase 2 enzyme families that comprise the xenobiotic-metabolising system (Williams, 1967). Generally, phase 1 enzymes from the cytochrome P (CYP) 450 family catalyse the activation of indirect-acting carcinogens, whereas phase 2 enzymes such as the glutathione S-transferases (GST) catalyse the detoxification of both direct-acting and indirect-acting carcinogens (Talalay \& Fahey, 2001). Thus, it has been suggested that shifting the balance of phase 1 and phase 2 enzymes in favour of the latter might be an effective chemoprevention strategy (Talalay, 2000). However, this hypothesis has been challenged for a number of reasons, including the fact that individual phase 2 enzymes often activate a specific class of chemicals (Paolini et al. 1999).

The induction of phase 2 enzymes has, however, been proposed as the major mechanism through which cruciferous vegetables protect against chemically induced tumours (Steinkellner et al. 2001; Jeffery \& Stewart, 2004). An extracolonic increase in phase 2 enzyme activity could protect the colon from carcinogens by reducing the delivery of partiallyactivated compounds from the systemic circulation (Pool-Zobel, 1999). Kassie et al. (2002, 2003a) have shown that in rodents exposed to the heterocyclic amine 2-amino-3methylimidazo[4,5- $f$ ]quinoline (IQ) the ability of juices prepared from cruciferous vegetables to protect against the induction of aberrant crypt foci (ACF) is correlated with their ability to increase the activity of the phase 2 enzyme
UDP-glucuronosyl transferase form 2 in the liver. Cruciferous vegetables may also exert their protective effects through a local induction of phase 2 enzymes in the large intestine. In human subjects the consumption of $300 \mathrm{~g}$ Brussels sprouts/d for 1 week results in the elevation of rectal GST- $\alpha$ and $-\pi$ isoenzymes (Nijhoff et al. 1995). Similarly, a diet containing $200 \mathrm{~g}$ freeze-dried broccoli (Brassica olearacea var. Majestic)/kg potently induces quinone reductase activity in the colonic mucosa of rodents (Keck et al. 2003).

Although cruciferous vegetables induce phase 2 enzymes, they also tend to induce phase 1 enzymes, particularly CYP1A1 and CYP1A2 (Vang et al. 1991, 2001; Wortelboer et al. 1992). The induction of CYP1A1 and CYP1A2 may sometimes be detrimental because they activate many carcinogens and may also increase the production of reactive oxygen species (Guengerich \& Shimada, 1998; Paolini et al. 2004). GLS breakdown products are probably the primary compounds responsible for the induction of xenobioticmetabolising enzymes after the consumption of cruciferous vegetables (Vang et al. 2001). Certain ITC, such as sulforaphane, appear to be potent monofunctional inducers of phase 2 enzymes (Fig. 1; Zhang et al. 1992). However, most cruciferous vegetables contain a range of GLS with variable modulatory effects on enzymes. For example, broccoli, which is the main dietary source of sulforaphane, also typically contains sizeable quantities of glucobrassicin and neo-glucobrassicin, which hydrolyse to form indole-3carbinol (I3C; Kushad et al. 1999; Mithen et al. 2000). On exposure to the acid environment of the stomach, I3C can undergo several condensation reactions to form a range of dimers, trimers, tetramers and oligomers (McDanell et al. 1988). In contrast to sulforaphane, I3C and its acid condensation products induce both phase 1 and phase 2 enzymes (Fig. 1; Shertzer \& Sainsbury, 1991; Nho \& Jeffery, 2004). The effect of cruciferous-vegetable consumption on phase 1 and phase 2 enzyme activities is likely to be unpredictable, varying according to the GLS composition of the vegetable (which is governed by genotype, growing conditions and post-harvest treatment) and possibly the content of other bioactive compounds present at the time of consumption (Vang et al. 2001; International Agency for Research on Cancer, 2004; Jeffery \& Stewart, 2004).

Evidence from animal models generally indicates that the joint induction of phase 1 and phase 2 enzymes by a variety of cruciferous vegetables results in a favourable metabolic profile for the elimination of certain chemical carcinogens (for a comprehensive review, see International Agency for Research on Cancer, 2004). However, it is unclear whether a similar chemoprotective effect would occur in free-living human subjects, who, in contrast to experimental animals, are chronically exposed to low doses of a wide variety of chemical carcinogens. The outcome of any shift in the balance of xenobiotic-metabolising enzymes is likely to be unpredictable, depending on the range of chemical carcinogens to which an individual is exposed (Paolini et al. 1999).

\section{Antioxidant effects}

The colonic epithelium may be subject to oxidative damage mediated by free radicals generated near its surface by the 


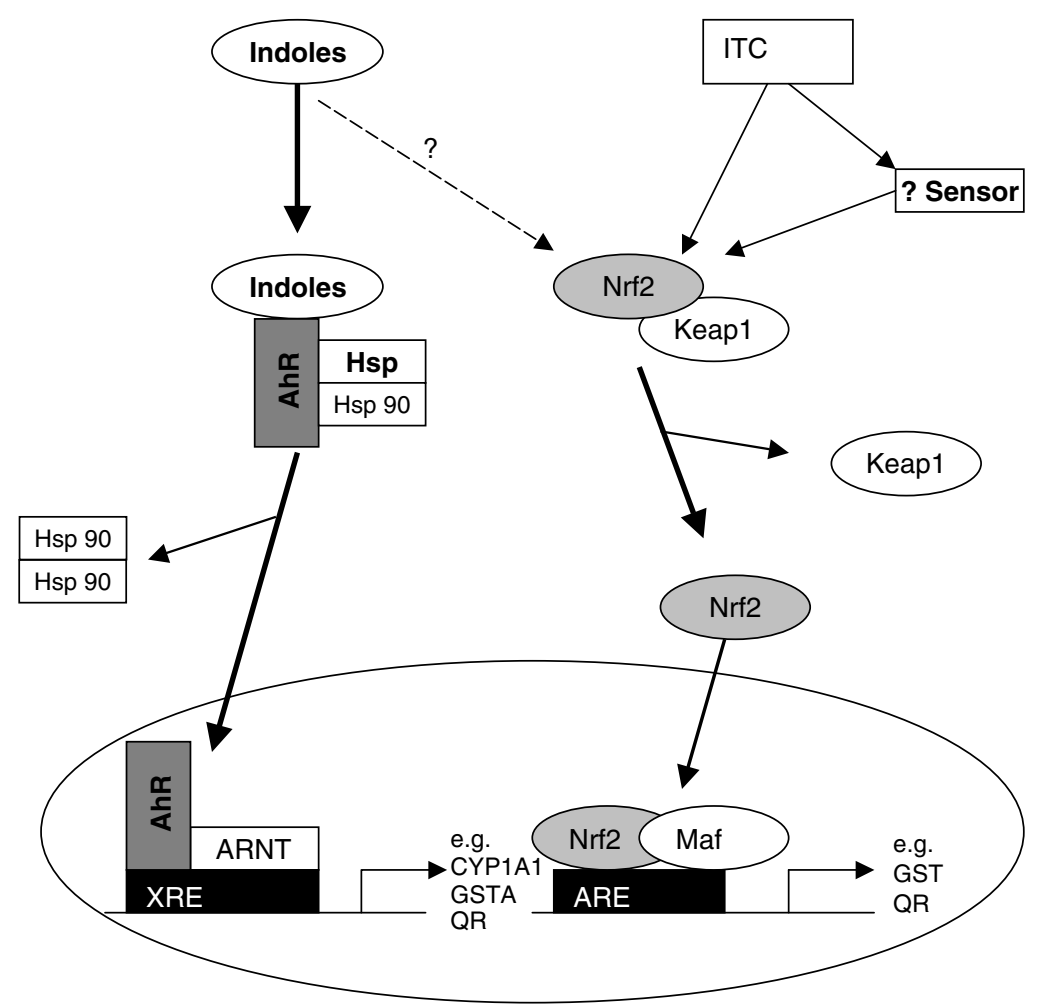

Fig. 1. Regulation of xenobiotic-metabolising enzymes by glucosinolates breakdown products (adapted from Hayes \& McMahon, 2001; Lampe \& Peterson, 2002). Isothiocyanates (ITC) are monofunctional inducers that interact with an antioxidant responsive element (ARE) that is present in the upstream enhancer region of the genes encoding a number of phase 2 enzymes such as quinone reductase (QR) and several glutathione S-transferases (GST) isoenzymes. Indoles have been classified as bifunctional inducers. Indoles enhance the transcription of a number of genes with xenobiotic-responsive elements (XRE) in their upstream enhancer regions, such as cytochrome P (CYP)1A1, CYP1A2, QR and GSTA. Indoles may also interact with the ARE possibly after metabolism by CYP450 or through some other as yet undefined mechanism (Hayes \& McMahon, 2001; Nho \& Jeffery, 2004). Hsp, heat-shock protein; AhR, aromatic hydrocarbon receptor; Nrf2, NF-E2-related factor-2; Keap1, Kelch-like $\mathrm{ECH}$-associated protein 1; Maf, musculoapo-neurotic fibrosarcoma; ARNT, aryl hydrocarbon receptor nuclear translator.

faecal matrix (Babbs, 1990; Stone et al. 2002). Cruciferous vegetables may contribute to the antioxidant defence of the colonic mucosa through non-enzymic and enzymic mechanisms. Various GLS breakdown products can interact with a common antioxidant-responsive element present in the upstream region of the genes encoding several phase 2 enzymes with known antioxidant actions, such as GST and quinone reductase (Fig. 1). Some cruciferous vegetables are also rich sources of carotenoids and polyphenolic compounds (Kurilich et al. 1999), which are antioxidants that are poorly absorbed in the proximal gastrointestinal tract and are therefore likely to reach the colon in substantial quantities (Halliwell et al. 2000). Within the colonic lumen, carotenoids and polyphenolic compounds may protect the colonic epithelium from free radical attack. Polyphenolic compounds may chelate $\mathrm{Fe}$, thereby helping to reduce the pro-oxidant effect of colonic $\mathrm{Fe}$, and both carotenoids and polyphenols may directly scavenge free radicals (Halliwell et al. 2000). Little work appears to have been conducted on the ability of cruciferous vegetables to alter the antioxidant activity of the large bowel. However, preliminary work has indicated that pigs consuming raw broccoli have an increased faecal antioxidant level, as measured by electron spin resonance (Ratcliffe et al. 2001).

\section{Induction of apoptosis}

The induction of apoptosis may confer protection against CRC at every stage of the adenoma-carcinoma sequence. Cells with mutational DNA damage may be removed before the mutation becomes fixed. Clonal expansion may be prevented by the removal of initiated cells, and even established lesions may regress (Takayama et al. 1998; Johnson, 2002b). Some evidence indicates that cruciferous vegetables and their GLS breakdown products may exert some of their anti-carcinogenic effects through the induction of apoptosis. In highly-proliferative HT29 human colon cancer cells sulforaphane induces apoptosis in a dose-dependent manner (Gamet-Payrastre et al. 2000). Furthermore, sinigrin and Brussels sprouts induce 
apoptosis in rodents when consumed after the administration of 1,2-dimethylhydrazine (DMH; Smith et al. 1998, 2003).

\section{Cell cycle arrest}

GLS breakdown products may be able to suppress cancer development in initiated cells by inhibiting cellular proliferation (Gamet-Payrastre et al. 2000; Smith et al. 2004). For example, allyl ITC causes human HT29 colo-rectal carcinoma cells to become blocked in the $\mathrm{G}_{2} \mathrm{M}$ phase (Smith et al. 2004).

\section{Cruciferous vegetables and experimental colon cancer}

In animal models of colon cancer, cruciferous vegetables have generally been shown to inhibit chemical carcinogenesis. Brussels sprouts in particular have been shown to be protective (Rijken et al. 1999; Kassie et al. 2003a; Smith et al. 2003; Uhl et al. 2004). Kassie and associates (Kassie et al. 2003a; Uhl et al. 2004) have investigated whether juices prepared from two varieties of Brussels sprouts ('Maximus' and 'Cyrus') could provide protection during both cancer initiation and promotion. For rats administered IQ by gavage on ten alternate days supplementation of their drinking water with Brussels sprout juices was found to inhibit the development of ACF. In a further study using the same carcinogen-dosing schedule, the consumption of juice prepared from 'Maximus' Brussels sprouts was found to inhibit the formation of ACF when consumed in the period after IQ exposure (Uhl et al. 2004). In contrast, juices prepared from two varieties of red cabbage ('Reliant' and 'Roxy') were found to be much less effective, exerting only a small non-significant inhibiting effect during the initiation period and no effect during the promotion period (Kassie et al. 2003a). The authors have hypothesised that the lack of effect of redcabbage juice might be explained by its $2-3$-fold lower content of GLS. However, in another study (Hagiwara et al. 2002) an extract of the colour from red cabbage (incorporated into the diet at a level of $50 \mathrm{~g} / \mathrm{kg}$ ) that is devoid of GLS was shown to inhibit adenoma and carcinoma formation in rats initiated with DMH and subsequently fed a diet containing the heterocyclic amine 2-amino-1-methyl-6-phenylimidazo[4,5-b]pyridine at a concentration of $0 \cdot 2 \mathrm{~g} / \mathrm{kg}$. The red-cabbage-colour extract was also found to protect against the formation of ACF in non-DMH-treated rats fed a diet containing 2-amino-1methyl-6-phenylimidazo[4,5-b]pyridine.

Other cruciferous vegetables have received relatively little attention. Single studies have found that garden cress (Lepidium sativum) juice and cruciferous seed meals and hulls are protective, whereas broccoli has been shown to have no effect (Barrett et al. 1998; Rijken et al. 1999; Kassie et al. 2002). The latter finding of no protective effect of broccoli against azoxymethane-induced ACF is somewhat surprising because the breakdown products of glucobrassicin and glucoraphanin, the major GLS found in broccoli, have been shown to inhibit azoxymethaneinduced ACF (Chung et al. 2000; Kim et al. 2003).
There are only two reports of a possible colon-cancerpromoting effect of cruciferous vegetables (Temple \& Basu, 1987; Temple \& El-Khatib, 1987). In these studies female Swiss mice fed a diet supplemented with cabbage during initiation with $\mathrm{DMH}$ or throughout the experimental period were reported to exhibit a modest increase in tumour formation, although in both cases the effect was not significant.

\section{Indoles and isothiocyanates}

A variety of GLS hydrolysis products, including I3C, sulforaphane and phenethyl ITC, have been investigated for their ability to inhibit chemically-induced colon cancer (Pence et al. 1986; Pereira \& Khoury 1991; Guo et al. 1995; Wargovich et al. 1996; Xu et al. 1996, 2001; Chung et al. 2000). There is consistent evidence that when heterocyclic amines are used to initiate colon cancer I3C is an effective inhibiting agent (Guo et al. 1995; Xu et al. 1996). For example, I3C fed at a level of $1 \mathrm{~g} / \mathrm{kg}$ diet during the initiation phase, post initiation or during the whole experimental period inhibits ACF in male F344 rats exposed to 2-amino-1-methyl-6-phenylimidazo[4,5-b]pyridine (Guo et al. 1995; Xu et al. 1996). Similarly, I3C fed at a level of $1 \mathrm{~g} / \mathrm{kg}$ diet inhibits the formation of IQ-induced ACF when fed to male F344 rats throughout the experimental period or during the post-initiation phase (Xu et al. 1996, 2001). However, there is some concern that when DMH is used to initiate colon cancer I3C may promote tumour formation. In an early study (Pence et al. 1986) an increased incidence of tumours (combined tally of small intestinal and colonic tumours) was found in rats fed $\mathrm{I} 3 \mathrm{C}$ in their diet at $1 \mathrm{~g} / \mathrm{kg}$ before, during and after $\mathrm{DMH}$ administration. In contrast, in a more recent study I3C was not found to promote tumour formation when administered after DMH exposure (Xu et al. 2001). A striking difference between the studies of $\mathrm{Xu}$ et al. (2001) and Pence et al. (1986) is the number of colon tumours found in the positive control group injected with DMH (87 and $0 \%$ respectively). Possible explanations include the higher DMH dose $(20 \mathrm{mg} / \mathrm{kg} v .10 \mathrm{mg} / \mathrm{kg})$ and a greater time lapse from the last dose to the rats being killed (45 weeks v. 16 weeks) in the study of $\mathrm{Xu}$ et al. (2001). No firm conclusion can be drawn about the promoting effect of I3C from the study of $\mathrm{Xu}$ et al. (2001) because the very high level of tumours in the positive control group would make it difficult to identify any tumour-promoting effect of I3C. However, it is evident that $\mathrm{I} 3 \mathrm{C}$ fails to exert a protective effect. Interestingly, I3C fed during the post-initiation phase inhibits ACF formation in male mice administered azoxymethane (a metabolite of $\mathrm{DMH}$ ), perhaps indicating a species-specific effect (Kim et al. 2003).

Chung et al. (2000) have compared the ability of sulforaphane, phenethyl ITC and their respective $\mathrm{N}$-acetylcysteine conjugates to prevent azoxymethane-induced ACF in male F344 rats. Sulforaphane and phenethyl ITC were both found to be effective at reducing total ACF and crypt multiplicity when administered during the initiation and promotion periods. In contrast, their respective $\mathrm{N}$-acetylcysteine conjugates were only found to be effective when fed during the post-initiation period. Surprisingly, phenethyl ITC-N-acetylcysteine was found to increase the 
formation of $\mathrm{ACF}$ when administered during the initiation period. In contrast to the study of Chung et al. (2000), two earlier studies have found no protective effect of phenethyl ITC against azoxymethane-induced ACF (Pereira \& Khoury, 1991; Wargovich et al. 1996).

\section{Epidemiological studies}

At least seven cohort studies have investigated the association between the intake of cruciferous or brassica vegetables and colon, rectal or combined CRC risk (summarised in Fig. 2). Overall, the cohort studies provide little evidence for a protective effect of cruciferous vegetable intake against cancer of the large intestine. In fact, the most striking observation is that almost without exception the relative risks cluster around 1 and the $95 \%$ CI encompass 1 . In only one study, in a Dutch population, is there a significant negative association between brassica vegetable consumption and colon cancer, and even then the effect is only observed in women (relative risk 0.51 $(95 \%$ CI $0.50,1 \cdot 13), P=0.05$ for trend; Voorrips et al. 2000). Furthermore, for rectal cancer brassica vegetable consumption is associated with an increased risk in women (relative risk 1.66 (95\% CI 0.94, 2.94), $P=0.05$ for trend). Of further concern, a study of male smokers in Finland has found a significant increase in colon-cancer risk in the highest quintile of intake (relative risk 1.6 (95\% CI 1.0, $2 \cdot 4), P=0.05$ for trend; Pietinen et al. 1999). However, the study population exhibited an atypical consumption pattern with almost no intake of green cruciferous vegetables and the highest overall consumption levels were very low, the median level in the highest category of intake being $38 \mathrm{~g} / \mathrm{d}$.

So what factors may explain why large-scale prospective epidemiological studies generally fail to support the hypothesis that cruciferous vegetables protect against colon cancer, whereas animal studies have generally observed chemoprotective effects and experimental studies have identified a number of plausible mechanisms of action? One factor that may need to be considered is that relatively large doses of cruciferous vegetables or GLS exhibit chemoprotection, but normal habitual levels of intake of cruciferous vegetables have no effect. However, a number of limitations in the published cohort studies may have reduced their sensitivity to detect a modest protective effect of cruciferous vegetable consumption. The cohort studies all used food-frequency questionnaires to measure cruciferous vegetable intake. When validated against repeated weighed intakes food-frequency questionnaires tend to perform badly in comparison with other methods of dietary assessment, overestimating vegetable consumption in particular (Bingham et al. 1994). The failure of foodfrequency questionnaires to accurately assess vegetable intake could lead to an overestimation of vegetable intake and/or misclassification of subjects into the wrong category of consumption. Consistent overestimation of intake among all subjects would not preclude studies from finding an association between cruciferous vegetable intake and CRC, but would create a false impression of the range of intake that does or does not have an effect on cancer risk. Despite the fact that cohort studies may have overestimated the intake

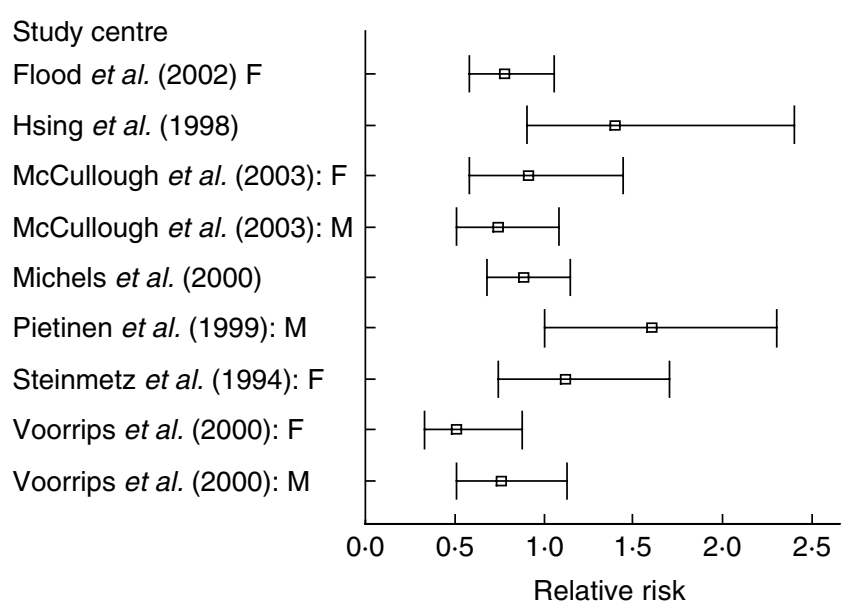

Fig. 2. Cohort studies of colon cancer and cruciferous vegetable consumption. Values are relative risks and $95 \% \mathrm{Cl}$ represented by horizontal bars. F, females; M, males.

of cruciferous vegetables, reported values are still low. For example, in the Cancer Prevention II study cohort, the highest quintile of cruciferous vegetable intake was reported to be half a portion or more per $\mathrm{d}$ in women and even lower in men (McCullough et al. 2003).

Misclassification of subjects is a potentially more serious problem than overestimation. Comparison of the ability of different methods of dietary assessment to classify individuals into the same quartile of consumption as $16 \mathrm{~d}$ weighed records indicates that food-frequency questionnaires correctly classify 30-50\% of individuals for most nutrients (Bingham et al. 1994). Such an extent of misclassification would attenuate relative-risk estimates and make modest protective effects very difficult to detect.

The ability of cruciferous vegetables to inhibit CRC may be influenced by the GST genotype of the individual (Lin et al. 1998; Slattery et al. 2000; Seow et al. 2002). Thus, the failure of the published cohort studies to consider the modulatory effect of GST genotype may have weakened their sensitivity to detect a protective effect of cruciferous vegetable consumption. The GST are involved in the detoxification of a range of chemical carcinogens and are responsible for the metabolism and excretion of ITC after cruciferous vegetable consumption (Hayes \& Pulford, 1995; Kolm et al. 1995). A recent nested case-control study has explored the relationship between cruciferous vegetable consumption (measured as ITC intake, using a semi-quantitative food-frequency questionnaire), genotype and CRC risk. In an initial comparison of 213 cases of CRC with 1194 controls selected from the prospective Singapore Chinese Health Study (Seow et al. 2002), only a small non-significant reduction in risk was found in subjects with the highest intake of ITC (odds ratio 0.81 $(95 \%$ CI $0.59,1.12))$. However, further stratification of subjects according to GST genotype has revealed a stronger significant protective effect of ITC consumption for CRC (odds ratio 0.43 (95\% CI 0.20, 0.96)) and particularly for colon cancer (odds ratio 0.31 (95\% CI 0.12 , 0.84)) among individuals with both GSTM1 and GSTT1 null genotypes, but no effect for individuals with a single 
null genotype. A protective effect in individuals with null genotypes and therefore reduced GST activity may seem counterintuitive because the up-regulation of GST activity is a mechanism through which cruciferous vegetables appear to inhibit chemical carcinogenesis (Steinkellner et al. 2001). However, individuals with GSTM1 and GSTT1 null genotypes may excrete ITC more slowly, leading to an accumulation of ITC in target tissues (Johnson, 2002a; Seow et al. 2002). ITC may then induce other chemoprotective phase 2 enzymes or exert other anti-carcinogenic effects, such as blocking the cell cycle or inducing apoptosis in cells carrying DNA damage (Johnson, 2002a; Seow et al. 2002).

Before consumption cruciferous vegetables are often stored or subjected to a range of treatments such as washing, chopping, blanching, freezing and cooking that may alter their biological effects. Variations in processing and storage may mean that individuals with similar levels of cruciferous vegetable intake are exposed to different levels of bioactive compounds. This variation could mask any association between cruciferous vegetable intake and CRC risk. Most types of post-harvest treatment result in a loss of bioactive compounds (Price et al. 1998; Conaway et al. 2000; Vallejo et al. 2002, 2003). Processing may also beneficially or negatively alter the bioavailability of such compounds. For example, the location and extent of GLS breakdown in the gastrointestinal tract and the profile of the breakdown products formed is influenced by the extent of thermal processing to which a vegetable is subjected before consumption (Johnson, 2002a; Matusheski et al. 2004). When raw or lightly-cooked cruciferous vegetables are consumed, most GLS hydrolysis occurs in the proximal gastrointestinal tract, catalysed by the presence of active plant myrosinase (Johnson, 2002a). However, the profile of the breakdown products formed after consumption of raw and lightly-cooked cruciferous vegetables may vary. A heat-labile cofactor epithiospecifier protein may favour the formation of nitriles over ITC after the consumption of raw cruciferous vegetables, whereas mild cooking may shift the balance in favour of ITC by inactivating epithiospecifier protein whilst conserving some myrosinase activity (Mithen et al. 2003; Matusheski et al. 2004). If myrosinase is inactivated by prolonged cooking, intact GLS will be delivered to the colon and degraded by the colonic microflora (some of which have myrosinase activity), resulting in the production of ITC and possibly other, as yet undetermined, breakdown products (Johnson, 2002a).

Only a few studies appear to have investigated the effect of processing on the actions of cruciferous vegetables in vivo. In a rodent study, juice or tissue prepared from raw Brussels sprouts has been shown to induce apoptosis and inhibit DMH-induced ACF, whereas blanched Brussels sprouts (with inactive myrosinase) have no effect (Smith et al. 2003). In contrast, Kassie et al. (2003a) have found that juices prepared from raw Brussels sprouts or Brussels sprouts that have been cooked for $10 \mathrm{~min}$ at $100^{\circ} \mathrm{C}$ are similarly as effective at inhibiting IQ-induced ACF. Juice prepared from raw Brussels sprouts would be expected to contain GLS breakdown products, whereas juice prepared from cooked Brussels sprouts would be expected to contain intact GLS and no active myrosinase. Kassie et al. (2003a) have suggested that the colonic microflora or the acidic conditions of the stomach facilitate the hydrolysis of the GLS in the cooked Brussels sprout juice. However, neither of these routes would be expected to be as effective at supplying anti-carcinogenic GLS breakdown products as consuming juice containing hydrolysed GLS breakdown products, so it is surprising that both juices have similar effects.

The effect of common industrial food-processing techniques on the effects of cruciferous vegetables in vivo has not been reported. An animal experiment has been conducted to investigate the effect of the commercial freezing process on the ability of broccoli to affect a variety of markers of possible relevance to CRC risk. The markers that were measured included xenobiotic-metabolising enzyme activities in the liver and colon, SCFA concentrations in colonic contents, alterations in the faecal microflora and DNA strand breakage in colonocytes. Pigs were fed diets supplemented with $600 \mathrm{~g}$ raw or blanchedfrozen broccoli (var. Marathon)/d for $12 \mathrm{~d}$. Neither of the broccoli treatments was found to alter the activity of any of the enzymes measured (Table 1; Lynn et al. 2005 ) or the total SCFA content and the ratio of individual SCFA in the colonic contents (A Lynn, Z Fuller, K Hillman and B Ratcliffe, unpublished results). Both raw and blanched-frozen broccoli were found to exert similar effects on the colonic microflora, reducing total coliform and Escherichia coli numbers (A Lynn, Z Fuller, K Hillman and B Ratcliffe, unpublished results). Surprisingly, it was found that raw broccoli consumption causes a significant $21 \%$ increase in DNA strand breaks in the colon $(P<0 \cdot 05)$, whereas blanched-frozen broccoli has no significant effect (Fig. 3). The lack of effect of the blanched-frozen broccoli indicates that the blanching-freezing process causes a loss of the bioactive component responsible for causing DNA damage and/or alters its supply to the colonocytes.

The damaging effect of raw broccoli consumption on colonocyte DNA has been confirmed in a second experiment. Pigs fed diets supplemented with a different variety of raw broccoli (var. Monaco) were found to exhibit a $50 \%$ increase in DNA strand breaks $(P<0.05$; A Lynn, A Collins, Z Fuller, K Hillman and B Ratcliffe, unpublished results). To investigate whether a raw vegetable devoid of GLS would cause DNA damage, a second group of pigs were fed supplemental raw carrots. Raw carrots had no significant effect (A Lynn, A Collins, Z Fuller, K Hillman and B Ratcliffe, unpublished results). These studies appear to be the first to find an increase in DNA damage in the colon of animals fed raw cruciferous vegetables. In contrast to these studies, Kassie et al. (2003b) have found that juice prepared from raw garden cress decreases DNA damage in the colon of rats. The different effect of garden cress juice and broccoli may be explained by variations in their content of bioactive compounds such as GLS. For example, garden cress is rich in glucotropaeolin, whereas broccoli typically contains sizeable quantities of glucobrassicin, glucoraphanin and gluconapin (Kushad et al. 1999; Kassie et al. 2003b). Whilst no other studies have reported an increase in DNA damage in the colon after the consumption of raw broccoli, one study has reported an increase in oxidative DNA damage (measured as 8-oxodeoxyguanosine) in the liver of rats fed an extract of cooked Brussels sprouts (Sorensen et al. 2001). 
Table 1. Activities of glutathione S-transferase (GST), quinone reductase (QR), ethoxyresorufin O-deethylation (EROD) and methoxyresorufin O-demethylation (MROD) in pigs following consumption of raw or blanched-frozen broccoli (from Lynn et al. 2005)*

(Values are means and standard deviations for five pigs)

\begin{tabular}{|c|c|c|c|c|c|c|}
\hline & \multicolumn{2}{|c|}{ Raw broccoli } & \multicolumn{2}{|c|}{ Blanched-frozen broccoli } & \multicolumn{2}{|c|}{ Control } \\
\hline & Mean & SD & Mean & SD & Mean & SD \\
\hline \multicolumn{7}{|l|}{ GST activity (nmol/min per mg protein): } \\
\hline Liver & $2108 \cdot 7$ & $549 \cdot 2$ & $2177 \cdot 6$ & 546.9 & $2213 \cdot 2$ & $254 \cdot 7$ \\
\hline Colon & $120 \cdot 3$ & $15 \cdot 7$ & $137 \cdot 6$ & $23 \cdot 2$ & $134 \cdot 9$ & 24.5 \\
\hline \multicolumn{7}{|l|}{ QR activity (nmol/min per $\mathrm{mg}$ protein): } \\
\hline Liver & $160 \cdot 0$ & $89 \cdot 2$ & $171 \cdot 3$ & $56 \cdot 5$ & $149 \cdot 1$ & $94 \cdot 3$ \\
\hline Colon & $133 \cdot 8$ & $25 \cdot 9$ & $130 \cdot 8$ & $27 \cdot 1$ & $106 \cdot 7$ & $30 \cdot 8$ \\
\hline \multicolumn{7}{|l|}{ EROD activity (pmol/min per $\mathrm{mg}$ protein): } \\
\hline Liver & $106 \cdot 1$ & $31 \cdot 9$ & $111 \cdot 6$ & $33 \cdot 8$ & $103 \cdot 2$ & $20 \cdot 8$ \\
\hline \multicolumn{7}{|l|}{ MROD activity (pmol/min per $\mathrm{mg}$ protein): } \\
\hline Liver & $38 \cdot 3$ & $9 \cdot 7$ & $39 \cdot 1$ & $9 \cdot 2$ & $37 \cdot 2$ & $5 \cdot 0$ \\
\hline
\end{tabular}

*The animals (five per treatment group) were fed diets unsupplemented (control) or supplemented with $600 \mathrm{~g}$ raw or blanched-frozen broccoli (var. Marathon)/d for $12 \mathrm{~d}$. All enzyme activities were determined in triplicate. Two-way ANOVA was used to assess statistical significance of differences.

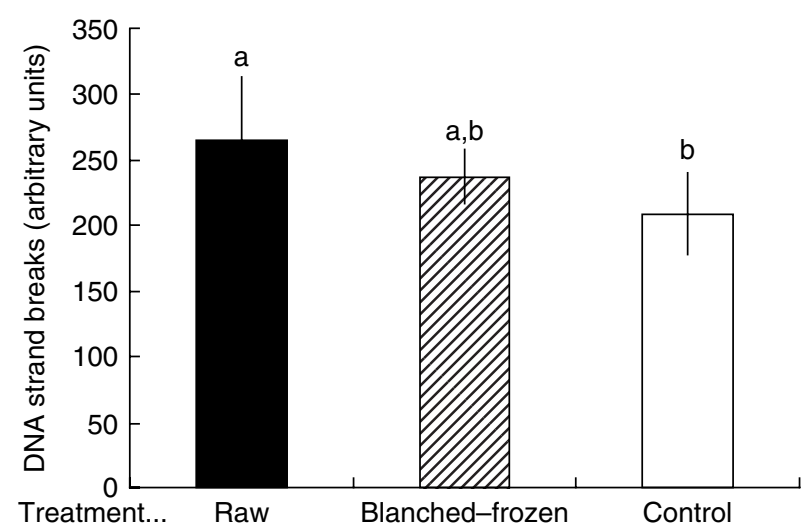

Fig. 3. The effect of raw and processed broccoli on the level of DNA strand breaks in the colonocytes of pigs. The animals (five per treatment group) were fed diets unsupplemented (control) or supplemented with $600 \mathrm{~g}$ raw or blanched-frozen broccoli (var. Marathon)/d for $12 \mathrm{~d}$. DNA damage was measured in cryopreserved colonocytes by single-cell gel electrophoresis (comet assay) using a modification of the method of Collins et al. (1993). Results are expressed as pooled mean values (in arbitrary units, scored 0-400) for each treatment group and standard deviations represented by vertical bars. Two-way ANOVA and the post-hoc Tukey test were used to assess statistical difference. ${ }^{\mathrm{a}, \mathrm{b}}$ Treatment groups with unlike superscript letters were significantly different $(P<0.05)$.

The mechanism through which raw broccoli may cause DNA damage in the colon of pigs is unclear. Evidence from studies in vitro and in vivo suggests that the induction of CYP450 enzymes, including CYP1A1 and CYP1A2, by GLS breakdown products may in some circumstances increase the production of reactive oxygen species and cause oxidative DNA damage (Park et al. 1996; Paolini et al. 2004). In the authors' studies, no increase in ethoxyresorufin $O$-deethylation or methoxyresorufin $O$-demethylation activity in the liver (possible measures of CYP1A1/2) has been observed; however, because CYP450 activities in the colon were not measured a local induction of
CYP450 cannot be ruled out, although a major induction seems unlikely.

There is some evidence that various GLS hydrolysis products can generate reactive oxygen species and cause DNA damage under certain circumstances (Murata et al. 2000). The $-\mathrm{N}=\mathrm{C}=\mathrm{S}$ group of ITC appears to be able to undergo spontaneous hydrolysis leading to the production of superoxide and $\mathrm{H}_{2} \mathrm{O}_{2}$ (Murata et al. 2000) and the presence of these pro-oxidants in colonocytes could lead to oxidative DNA damage. The hydrolysis of certain GLS present in raw broccoli may result in the generation of nitriles (Mithen et al. 2003; Matusheski et al. 2004). It has been speculated that nitriles have toxic effects and they may have contributed to the genotoxic effect observed with raw broccoli. It is also possible that other, unidentified, compounds present in raw broccoli may have been responsible.

\section{Conclusion}

Experimental studies have identified a number of plausible mechanisms through which cruciferous vegetables may protect against CRC. Also, high intakes of cruciferous vegetables, GLS and their breakdown products have consistently been shown to protect against colon cancer in animal models. However, the results from epidemiological cohort studies have been unconvincing, which may reflect a lack of sensitivity of these studies to detect an effect. Stratifying populations according to GST genotype appears to strengthen the negative association between cruciferous vegetable consumption and CRC risk. Considering how a vegetable has been processed before consumption may also increase the sensitivity of epidemiological studies. Conversely, the lack of a negative association between cruciferous vegetable intake and CRC in epidemiological studies may indicate that normal intakes of cruciferous vegetables do not exert chemoprotective effects.

In animal experiments $600 \mathrm{~g}$ raw broccoli (equivalent to five large servings)/d has been found to exhibit a genotoxic effect, increasing DNA strand breakage in colonocytes. The 
relevance of this finding to cancer risk is unclear. However, further investigations are warranted to identify the compounds responsible and their mechanism(s) of action.

\section{Acknowledgements}

A. L. was supported by a stipend from The Robert Gordon University, Aberdeen. The studies were funded by the World Cancer Research Fund. Animal facilities were provided by the Rowett Research Institute, Aberdeen.

\section{References}

Babbs CF (1990) Free-radicals and the etiology of colon cancer. Free Radical Biology and Medicine 8, 191-200.

Barrett JE, Klopfenstein CF \& Leipold HW (1998) Protective effects of cruciferous seed meals and hulls against colon cancer in mice. Cancer Letters 127, 83-88.

Bingham S, Day NE, Luben R, Ferrari P, Slimani N, Norat T et al. (2003) Dietary fibre in food and protection against colorectal cancer in the European Prospective Investigation into Cancer and Nutrition (EPIC): an observational study. Lancet 361, 1496-1501.

Bingham SA (2000) Diet and colorectal cancer prevention. Biochemical Society Transactions 28, 12-16.

Bingham SA, Gill C, Welch A, Day K, Cassidy A, Khaw KT, Sneyd MJ, Key TJA, Roe L \& Day NE (1994) Comparison of dietary assessment methods in nutritional epidemiology-weighed records $\mathrm{v}$ 24-h recalls, food-frequency questionnaires and estimated-diet records. British Journal of Nutrition 72, 619-643.

Bones AM \& Rossiter JT (1996) The myrosinase-glucosinolate system, its organisation and biochemistry. Physiologia Plantarum 97, 194-208.

Chung FL, Conaway CC, Rao CV \& Reddy BS (2000) Chemoprevention of colonic aberrant crypt foci in Fischer rats by sulforaphane and phenethyl isothiocyanate. Carcinogenesis 21, 2287-2291.

Collins AR, Duthie SJ \& Dobson VL (1993) Direct enzymatic detection of endogenous oxidative base damage in human lymphocyte DNA. Carcinogenesis 14, 1733-1735.

Colditz GA, Cannuscio CC \& Frazier AL (1997) Physical activity and reduced risk of colon cancer: implications for prevention. Cancer Causes \& Control 8, 649-667.

Conaway CC, Getahun SM, Liebes LL, Pusateri DJ, Topham DKW, Botero-Omary M \& Chung FL (2000) Disposition of glucosinolates and sulforaphane in humans after ingestion of steamed and fresh broccoli. Nutrition and Cancer 38, 168-178.

DeSouza S \& Eitenmiller RR (1986) Effects of processing and storage on the folate content of spinach and broccoli. Journal of Food Science 51, 626-628.

Flood A, Velie EM, Chaterjee N, Subar AF, Thompson FE, Lacey JV, Schairer C, Troisi R \& Schatzkin A (2002) Fruit and vegetable intakes and the risk of colorectal cancer in the Breast Cancer Detection Demonstration Project follow-up cohort. American Journal of Clinical Nutrition 75, 936-943.

Gamet-Payrastre L, Li P, Lumeau S, Cassar G, Dupont MA, Chevolleau S, Gasc N, Tulliez J \& Terce F (2000) Sulforaphane, a naturally occurring isothiocyanate, induces cell cycle arrest and apoptosis in HT29 human colon cancer cells. Cancer Research 60, 1426-1433.

Giovannucci E (2001) An updated review of the epidemiological evidence that cigarette smoking increases risk of colorectal cancer. Cancer Epidemiology, Biomarkers \& Prevention 10, 725-731.

Giovannucci E, Rimm EB, Stampfer MJ, Colditz GA, Ascherio A \& Willet WC (1994) Aspirin use and the risk for colorectal cancer and adenoma in male health professionals. Annals of Internal Medicine 121, 214-246.

Guengerich FP \& Shimada T (1998) Activation of procarcinogens by human cytochrome P450 enzymes. Mutation Research 400, 201-213.

Guo D, Schut HA, Davis CD, Snyderwine EG, Bailey GS \& Dashwood RH (1995) Protection by chlorophyllin and indole3-carbinol against 2-amino-1-methyl-6-phenylimidazo[4,5-b] pyridine (Phip)-induced DNA adducts and colonic aberrant crypts in the F344 rat. Carcinogenesis 16, 2931-2937.

Hagiwara A, Yoshino H, Ichihara T, Kawabe M, Taman S, Aoki H, Koda T, Nakamura M, Imaida K, Ito N \& Shirai T (2002) Prevention by natural food anthocyanins, purple sweet potato color and red cabbage color, of 2-amino-1-methyl-6-phenylimidazo[4,5- $b$ ]pyridine (Phip)-associated colorectal carcinogenesis in rats with 1,2-dimethylhydrazine. Journal of Toxicological Sciences 27, 57-68.

Halliwell B, Zhao K \& Whiteman M (2000) The gastrointestinal tract: A major site of antioxidant action? Free Radical Research 33, 819-830.

Hayes JD \& McMahon M (2001) Molecular basis for the contribution of the antioxidant responsive element to cancer chemoprevention. Cancer Letters 174, 103-113.

Hayes JD \& Pulford DJ (1995) The glutathione S-transferase supergene family: Regulation of GST and the contribution of the isoenzymes to cancer chemoprotection and drug resistance. Critical Reviews in Biochemistry and Molecular Biology 30, 445-600.

Hodgson E \& Akunda A (2001) Carcinogenesis. In Introduction to Toxicology, pp. 343-395 [E Hodgson and RC Smart, editors]. New York: Wiley.

Holst B \& Williamson G (2004) A critical review of the bioavailability of glucosinolates and related compounds. Natural Product Reports 21, 425-447.

Hsing AW, McLaughlin JK, Chow WH, Schuman LM, Chien HTC, Gridley G, Bielke E, Wacholder S \& Blot WJ (1998) Risk factors for colorectal cancer in a prospective study among US white men. International Journal of Cancer 77, 549-553.

International Agency for Research on Cancer (2003) Fruit and Vegetables. IARC Handbooks of Cancer Prevention no. $8[\mathrm{H}$ Vainio and F Bianchini, editors]. Lyon, France: IARC Press.

International Agency for Research on Cancer (2004) Cruciferous Vegetables, Isothiocyanates and Indoles. IARC Handbooks of Cancer Prevention no. 9 [H Vainio and F Bianchini, editors]. Lyon, France: IARC Press.

Jeffery EH \& Stewart KE (2004) Upregulation of quinone reductase by glucosinolate hydrolysis products from dietary broccoli. Methods in Enzymology 382, 457-469.

Johnson IT (2002a) Glucosinolates: bioavailability and importance to health. International Journal of Vitamins and Nutrition Research 72, 26-31.

Johnson IT (2002b) Anticarcinogenic effects of diet-related apoptosis in the colorectal mucosa. Food and Chemical Toxicology 40, 1171-1178.

Kassie F, Rabot S, Uhl M, Huber W, Qin HM, Helma C, SchulteHermann R \& Knasmuller S (2002) Chemoprotective effects of garden cress (Lepidium sativum) and its constituents towards 2-amino-3-methyl-imidazo[4,5-f]quinoline (IQ)-induced genotoxic effects and colonic preneoplastic lesions. Carcinogenesis 23, 1155-1161.

Kassie F, Uhl M, Rabot S, Grasl-Kraupp B, Verkerk R, Kundi M, Chabicovsky M, Schulte-Hermann R \& Knasmuller S (2003a) Chemoprevention of 2-amino-3-methylimidazo [4,5-f]quinoline (IQ)-induced colonic and hepatic preneoplastic lesions in the F344 rat by cruciferous vegetables administered simultaneously with the carcinogen. Carcinogenesis 24, 255261. 
Kassie F, Laky B, Gminski R, Mersch-Sundermann V, Scharf G, Lhoste E \& Kansmuller S (2003b) Effects of garden and water cress juices and their constituents, benzyl and phenethyl isothiocyanates, towards benzo(a)pyrene-induced DNA damage: a model study with the single cell gel electrophoresis/Hep G2 assay. Chemico-Biological Interactions 142, 285-296.

Keck AS, Qiao QY \& Jeffery EH (2003) Food matrix effects on bioactivity of broccoli-derived sulforaphane in liver and colon of F344 rats. Journal of Agricultural and Food Chemistry 51, $3320-3327$.

Kim DJ, Shin DH, Ahn B, Kang JS, Nam KT, Park CB et al. (2003) Chemoprevention of colon cancer by Korean food plant components. Mutation Research 523, 99-107.

Kohlmeier L \& Su L (1997) Cruciferous vegetables consumption and colorectal cancer risk: meta-analysis of the epidemiological evidence. FASEB Journal 11, A369.

Kolm RH, Danielson VH, Zhang Y, Talalay P \& Mannervik B (1995) Isothiocyanates as substrates for human glutathione S-transferases: structure-activity studies. Biochemical Journal 311, 453-459.

Kurilich AC, Tsau GJ, Brown A, Howard L, Klein BP, Jeffery EH, Kushad M, Wallig MA \& Juvik JA (1999) Carotene, tocopherol, and ascorbate contents in subspecies of Brassica oleracea. Journal of Agricultural and Food Chemistry 47, $1576-1581$

Kushad MM, Brown AF, Kurilich AC, Juvik JA, Klein BP, Wallig MA \& Jeffery EH (1999) Variation of glucosinolates in vegetable crops of Brassica oleracea. Journal of Agricultural and Food Chemistry 47, 1541-1548.

Lampe JW \& Peterson S (2002) Brassica, biotransformation and cancer risk: Genetic polymorphisms alter the preventive effects of cruciferous vegetables. Journal of Nutrition 132, 2991-2994.

Lin HJ, Probst-Hensch NM, Louie AD, Kau IH, Witte JS, Ingles SA, Frankl HD, Lee ER \& Haile RW (1998) Glutathione transferase null genotype, broccoli and lower prevalence of colorectal adenomas. Cancer Epidemiology, Biomarkers \& Prevention 7, 647-652.

Lynch HT \& de la Chapelle A (2003) Hereditary colorectal cancer. The New England Journal of Medicine 348, 919-932.

Lynn A, Fuller Z, Hillman K \& Ratcliffe B (2005) Broccoli consumption has no effect on xenobiotic metabolising enzymes. Proceedings of the Nutrition Society 64, 66A.

McCullough ML, Robertson AS, Chao A, Jacobs EJ, Stampfer MJ, Jacobs DR, Diver WR, Calle EE \& Thun MJ (2003) A prospective study of whole grains, fruits, vegetables and colon cancer risk. Cancer Causes \& Control 14, 959-970.

McDanell R, McLean AE, Hanley AB, Heaney RK \& Fenwick GR (1988) Chemical and biological properties of indole glucosinolates (glucobrassicins): a review. Food and Chemical Toxicology 26, 59-70.

Matusheski NV, Juvik JA \& Jeffery EH (2004) Heating decreases epithiospecifier protein activity and increases sulforaphane formation in broccoli. Phytochemistry 65, 1273-1281.

Michels KB, Giovannucci E, Kaumudi JJ, Rosner BA, Stampfer MJ, Fuchs CS, Colditz GA, Speizer FE \& Willett WC (2000) Prospective study of fruit and vegetable consumption and incidence of colon and rectal cancers. Journal of the National Cancer Institute 92, 1740-1752.

Mithen R, Faulkner K, Magrath R, Rose P, Williamson G \& Marquez J (2003) Development of isothiocyanate-enriched broccoli and its enhanced ability to induce phase 2 detoxification enzymes in mammalian cells. Theoretical and Applied Genetics 106, 727-734.

Mithen RF, Dekker M, Verkerk R, Rabot S \& Johnson IT (2000) The nutritional significance, biosynthesis and bioavailability of glucosinolates in human foods. Journal of the Science of Food and Agriculture 80, 967-984.
Murata M, Yamashita N, Inoue S \& Kawanishi S (2000) Mechanism of oxidative DNA damage induced by carcinogenic allyl isothiocyanate. Free Radical Biology and Medicine 28, 797-805.

Nho CW \& Jeffery E (2004) Crambene, a bioactive nitrile derived from glucosinolate hydrolysis, acts via the antioxidant response element to upregulate quinone reductase alone or synergistically with indole-3-carbinol. Toxicology and Applied Pharmacology 198, 40-48.

Nijhoff WA, Grubben M, Nagengast FM, Jansen J, Verhagen H, Vanpoppel G \& Peters WHM (1995) Effects of consumption of brussels-sprouts on intestinal and lymphocytic glutathione s-transferases in humans. Carcinogenesis 16, 2125-2128.

Paolini M, Biagi GL \& Cantelli-Forti G (1999) The many consequences of chemical- and genetic-based modulation of drug metabolizing enzyme activities. Life Sciences 65, PL75-PL79.

Paolini M, Perocco P, Canistro D, Valgimigli L, Pedulli GF, Iori R, Croce CD, Cantelli-Forti G, Legator MS \& Abdel-Rahman SZ (2004) Induction of cytochrome P450, generation of oxidative stress and in vitro cell-transforming and DNA-damaging activities by glucoraphanin, the bioprecursor of the chemopreventive agent sulforaphane found in broccoli. Carcinogenesis 25, 61-67.

Park JYK, Shigenaga MK \& Ames BN (1996) Induction of cytochrome P4501A1 by 2,3,7,8-tetrachlorodibenzo-p-dioxin or indolo(3,2-b)carbazole is associated with oxidative DNA damage. Proceedings of the National Academy of Sciences USA 93, 2322-2327.

Pence BC, Buddingh F \& Yang SP (1986) Multiple dietary factors in the enhancement of dimethylhydrazine carcinogenesis - main effect of indole-3-carbinol. Journal of the National Cancer Institute 77, 269-276.

Pereira MA \& Khoury MD (1991) Prevention by chemopreventive agents of azoxymethane-induced foci of aberrant crypts in rat colon. Cancer Letters 61, 27-33.

Pietinen P, Malila N, Virtanen M, Hartman TJ, Tangrea JA, Albanes D \& Virtamo J (1999) Diet and risk of colorectal cancer in a cohort of Finnish men. Cancer Causes \& Control 10, 387-396.

Plumb GW, Price KR, Rhodes MJC \& Williamson G (1997) Antioxidant properties of the major polyphenolic compounds in broccoli. Free Radical Research 27, 429-435.

Pool-Zobel BL (1999) Diet and biotransformation of carcinogenic compounds in the gut by enzymes of microflora and of intestinal cells. In Colonic Microbiota, Nutrition and Health, pp. 245-255 [GR Gibson and MB Roberfroid, editors]. Dordecht and London: Kluwer Academic Publishers.

Price KR, Casuscelli F, Colquhoun IJ \& Rhodes MJC (1998) Composition and content of flavonol glycosides in broccoli florets (Brassica olearacea) and their fate during cooking. Journal of the Science of Food and Agriculture 77, 468-472.

Quinn M, Babbs P \& Brock A (2001) Cancer Trends in England and Wales, 1950-1999. London: The Stationery Office.

Ratcliffe B, McPhail DB, Collins A, Glass H, Reaper S \& Hillman K (2001) Analysis of faecal antioxidant activity using electron spin resonance spectroscopy as a proxy measure of colorectal cancer risk. Annals of Nutrition and Metabolism 45, Suppl. 1, 324.

Rijken PJ, Timmer WG, van de Kooij AJ, van Benschop IM, Wiseman SA, Meijers M \& Tijburg LBM (1999) Effect of vegetable and carotenoid consumption on aberrant crypt multiplicity, a surrogate end-point marker for colorectal cancer in azoxymethane-induced rats. Carcinogenesis 20, 2267-2272.

Seow A, Yuan JM, Sun CL, Van den Berg D, Lee HP \& Yu MC (2002) Dietary isothiocyanates, glutathione S-transferase polymorphisms and colorectal cancer risk in the Singapore Chinese Health Study. Carcinogenesis 23, 2055-2061. 
Shertzer HG \& Sainsbury M (1991) Chemoprotective and hepatic enzyme-induction properties of indole and indenoindole antioxidants in rats. Food and Chemical Toxicology 29, 391-400.

Slattery ML, Kampman E, Samowitz W, Caan BJ \& Potter JD (2000) Interplay between dietary inducers of GST and the GSTM-1 genotype in colon cancer. International Journal of Cancer 87, 728-733.

Smith TK, Lund EK, Clarke RG, Bennett RN \& Johnson IT (2005) Effects of Brussels sprout juice on the cell cycle and adhesion of human colorectal carcinoma cells (HT29) in vitro. Journal of Agricultural and Food Chemistry 53, 3895-3901.

Smith TK, Lund EK \& Johnson IT (1998) Inhibition of dimethylhydrazine-induced aberrant crypt foci and induction of apoptosis in rat colon following oral administration of the glucosinolate sinigrin. Carcinogenesis 19, 267-273.

Smith TK, Lund EK, Parker ML, Clarke RG \& Johnson IT (2004) Allyl-isothiocyanate causes mitotic block, loss of cell adhesion and disrupted cytoskeletal structure in HT29 cells. Carcinogenesis 25, 1409-1415.

Smith TK, Mithen R \& Johnson IT (2003) Effects of Brassica vegetable juice on the induction of apoptosis and aberrant crypt foci in rat colonic mucosal crypts in vivo. Carcinogenesis $\mathbf{2 4}$, 491-495.

Sorensen M, Jensen BR, Poulsen HE, Deng XS, Tygstrup N, Dalhoff K \& Loft S (2001) Effects of a Brussels sprouts extract on oxidative DNA damage and metabolising enzymes in rat liver. Food and Chemical Toxicology 39, 533-540.

Steinkellner H, Rabot S, Freywald C, Nobis E, Scharf G, Chabicovsky M, Knasmuller S \& Kassie F (2001) Effect of cruciferous vegetables and their constituents on drug metabolizing enzymes involved in the bioactivation of DNA-reactive dietary carcinogens. Mutation Research 480-1, 285-297.

Steinmetz KA, Kushi LH, Bostick RM, Folsom AR \& Potter JD (1994) Vegetables, fruit, and colon-cancer in the Iowa Womens Health Study. American Journal of Epidemiology 139, $1-15$.

Steinmetz KA \& Potter JD (1996) Vegetables, fruit, and cancer prevention: A review. Journal of the American Dietetic Association 96, 1027-1039.

Stone W, Papas A, LeClair I, Quin M \& Ponder T (2002) The influence of dietary iron and tocopherols on oxidative stress and ras-p21 levels in the colon. Cancer Detection and Prevention 26, 78-84.

Takayama T, Katsuki S, Takahashi Y, Ohi M, Nojiri S, Sakamaki S, Kato J, Kogawa K, Miyake H \& Niitsu Y (1998) Aberrant crypt foci of the colon as precursors of adenoma and cancer. New England Journal of Medicine 339, 1277-1284.

Talalay P (2000) Chemoprotection against cancer by induction of Phase 2 enzymes. Biofactors 12, 5-11.

Talalay P \& Fahey JW (2001) Phytochemicals from cruciferous plants protect against cancer by modulating carcinogen metabolism. Journal of Nutrition 131, 3027S-3033S.

Temple NJ \& Basu TK (1987) Selenium and cabbage and colon carcinogenesis in mice. Journal of the National Cancer Institute 26, 1131-1134.

Temple NJ \& El Khatib SM (1987) Cabbage and vitamin-E their effect on colon-tumor formation in mice. Cancer Letters 35, 71-77.

Uhl M, Kassie F, Rabot S, Grasl-Kraupp B, Chakraborty A, Laky B, Kundi M \& Knasmuller S (2004) Effect of common Brassica vegetables (Brussels sprouts and red cabbage) on the development of preneoplastic lesions induced by 2-amino-3-methylimidazo[4,5-f]quinoline (IQ) in liver and colon of Fischer 344 rats. Journal of Chromatography 802B 225-230.

Vallejo F, Tomas-Barberan FA \& Garcia-Viguera C (2002) Glucosinolates and vitamin $\mathrm{C}$ content in edible parts of broccoli florets after domestic cooking. European Food Research and Technology 215, 310-316.

Vallejo F, Tomas-Barberan F \& Garcia-Viguera C (2003) Healthpromoting compounds in broccoli as influenced by refrigerated transport and retail sale period. Journal of Agricultural and Food Chemistry 51, 3029-3034.

Vang O, Frandsen H, Hansen KT, Sorensen JN, Sorensen H \& Andersen O (2001) Biochemical effects of dietary intakes of different broccoli samples. I. Differential modulation of cytochrome P-450 activities in rat liver, kidney and colon. Metabolism 50, 1123-1129.

Vang O, Jensen H \& Autrup H (1991) Induction of cytochromeP-450ia1, cytochrome-P-450ia2, cytochrome-P-450iib1, cytochrome-P-450iib2 and cytochrome-P-450iie1 by broccoli in rat-liver and colon. Chemico-Biological Interactions $\mathbf{7 8}$, 85-96.

van Poppel G, Verhoeven DTH, Verhagen H \& Goldbohm RA (1999) Brassica vegetables and cancer prevention: Epidemiology and mechanisms. Advances in Experimental Medicine and Biology 472, 159-168.

Verhoeven DTH, Goldbohm RA, van Poppel G, Verhagen H \& van den Brandt PA (1996) Epidemiological studies on brassica vegetables and cancer risk. Cancer Epidemiology, Biomarkers \& Prevention 5, 733-748.

Verhoeven DTH, Verhagen H, Goldbohm RA, vandenBrandt PA \& vanPoppel G (1997) A review of mechanisms underlying anticarcinogenicity by brassica vegetables. Chemico-Biological Interactions 103, 79-129.

Voorrips LE, Goldbohm RA, van Poppel G, Sturmans F, Hermus RJJ \& van den Brandt PA (2000) Vegetable and fruit consumption and risks of colon and rectal cancer in a prospective cohort study. American Journal of Epidemiology 152, 10811092.

Wargovich MJ, Chen CD, Jimenez A, Steele VE, Velasco M, Stephens LC, Price R, Gray K \& Kelloff GJ (1996) Aberrant crypts as a biomarker for colon cancer: Evaluation of potential chemopreventive agents in the rat. Cancer Epidemiology, Biomarkers \& Prevention 5, 355-360.

Williams RT (1967) Comparative patterns of drug metabolism. Federation Proceedings 26, 659-665.

World Cancer Research Fund (1997) Food, Nutrition and the Prevention of Cancer: A Global Perspective. [J Potter, editor]. Washington, DC: American Institute of Cancer Research.

Wortelboer HM, Dekruif CA, Vaniersel AAJ, Noordhoek J, Blaauboer BJ, Vanbladeren PJ \& Falke HE (1992) Effects of cooked brussels-sprouts on cytochrome-P-450 profile and phase-II enzymes in liver and small intestinal-mucosa of the rat. Food and Chemical Toxicology 30, 17-27.

Xu M, Bailey AC, Hernaez JF, Taoka CR, Schut HAJ \& Dashwood RH (1996) Protection by green tea, black tea, and indole-3-carbinol against 2-amino-3-methylimidazo[4,5-f] quinoline-induced DNA adducts and colonic aberrant crypts in the F344 rat. Carcinogenesis 17, 1429-1434.

Xu MR, Orner GA, Bailey GS, Stoner GD, Horio DT \& Dashwood RH (2001) Post-dimethylhydrazine or 2-amino-3methylimidazo[4,5-f]quinoline. Carcinogenesis 22, 309-314.

Zhang Y, Talalay P, Cho CG, Posner GH (1992) A major inducer of anticarcinogenic protective enzymes from broccoli: Isolation and elucidation of structure. Proceedings of the National Academy of Sciences USA 89, 2399-2403. 